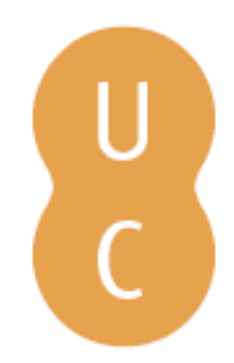

\title{
pommalina
}

\section{República Federal da Nigéria}

Autor(es): $\quad$ Lopes, Paula Duarte; Nascimento, Daniela

Publicado por: Imprensa da Universidade de Coimbra

URL

persistente: URI:http://hdl.handle.net/10316.2/38498

DOI: $\quad$ DOI:http://dx.doi.org/10.14195/978-989-26-0995-9_12

Accessed : $\quad$ 26-Apr-2023 11:26:08

A navegação consulta e descarregamento dos títulos inseridos nas Bibliotecas Digitais UC Digitalis, UC Pombalina e UC Impactum, pressupõem a aceitação plena e sem reservas dos Termos e Condições de Uso destas Bibliotecas Digitais, disponíveis em https://digitalis.uc.pt/pt-pt/termos.

Conforme exposto nos referidos Termos e Condições de Uso, o descarregamento de títulos de acesso restrito requer uma licença válida de autorização devendo o utilizador aceder ao(s) documento(s) a partir de um endereço de IP da instituição detentora da supramencionada licença.

Ao utilizador é apenas permitido o descarregamento para uso pessoal, pelo que o emprego do(s) título(s) descarregado(s) para outro fim, designadamente comercial, carece de autorização do respetivo autor ou editor da obra.

Na medida em que todas as obras da UC Digitalis se encontram protegidas pelo Código do Direito de Autor e Direitos Conexos e demais legislação aplicável, toda a cópia, parcial ou total, deste documento, nos casos em que é legalmente admitida, deverá conter ou fazer-se acompanhar por este aviso.

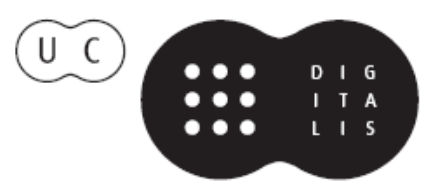




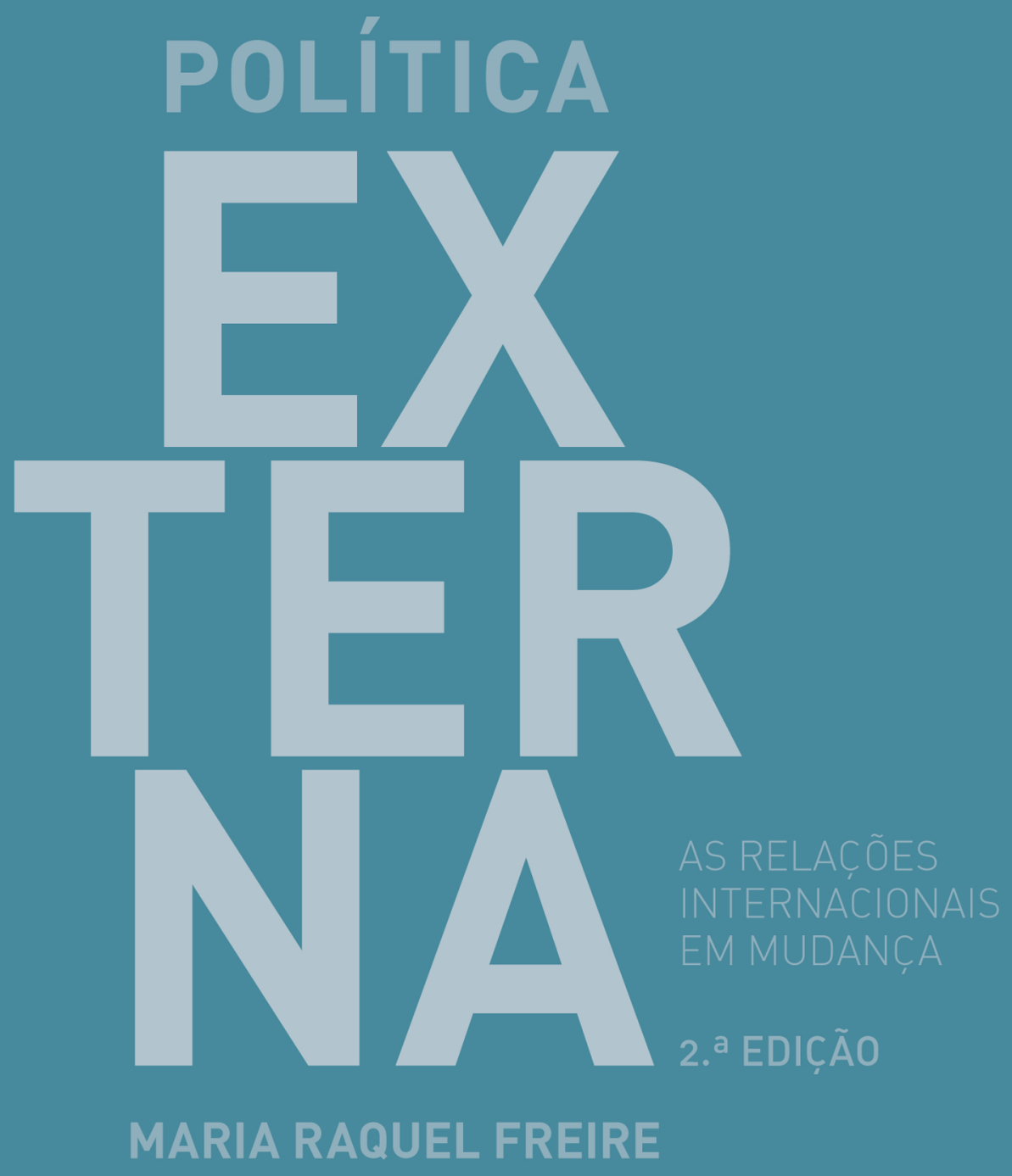

COORDENAÇÃO 


\section{CA P ÍTULO 12}

\section{REPÚBLICA FEDERAL DA NIGÉRIA}

Paula Duarte Lopes

e Daniela Nascimento

Desde a independência da Nigéria (1960) que o seu potencial para liderar o continente africano tem sido reconhecido e discutido internacionalmente. Os sucessivos governantes do país sempre incorporaram nas suas políticas externas a ideia da Nigéria como a 'líder natural' do continente africano. Este potencial tem-lhe valido inclusivamente a designação de 'Gigante de África'. A ideia de que a Nigéria está destinada a ser o líder da África negra baseia-se no facto de este ser o país mais populoso do continente africano, com cerca de 167 milhões de habitantes (com uma população jovem e em rápido crescimento), a segunda maior economia da África subsaariana (a seguir à África do Sul) (African Development Bank, 2013) o maior produtor de petróleo de África e um dos dez maiores exportadores de petróleo do mundo 98 . De acordo com notícias de abril de 2014 , pela primeira vez em duas décadas, a economia nigeriana ultrapassou a sul-africana, tornando-se a maior economia do continente africa-

98 Informações facultadas pelo Banco Mundial. [siteresources.worldbank. org/DATASTATISTICS/Resources/GDP_PPP.pdf] e pela US Energy Information Administration [tonto.eia.doe.gov/country/index.cfm] (consultado a 14 de março de 2015). 
no (BBC, 2014; Bloomberg, 2014). A Nigéria possui igualmente um dos mais importantes mercados consumidores do continente, com uma classe média em crescimento (Ford, 2012). Além disso, é ainda considerada uma das chamadas potências emergentes do grupo dos 'next-eleven' (Goldman Sachs, 2007a; 2007b) que incluem, entre outros, países como o Egito, a Indonésia, a Turquia ou a Coreia do Sul, desafiando portanto a exclusividade dos BRICS (Brasil, Rússia, Índia, China e África do Sul) como as potências emergentes internacionalmente reconhecidas. O objetivo de liderança regional e continental tem marcado a estratégia de formulação da política externa nigeriana nas suas cinco décadas de existência, ainda que nem sempre de forma coerente ou eficaz.

A política externa de qualquer país é condicionada pelo seu processo de tomada de decisão, pela natureza do sistema político, pela personalidade dos seus governantes, pelos recursos disponíveis e pela natureza do sistema internacional ${ }^{99}$. No caso da Nigéria, a evolução da sua política externa tem sido particularmente marcada pela personalidade dos seus sucessivos líderes, inclusivamente como uma extensão das suas ambições pessoais. Em teoria, os fatores que condicionam a formulação da política externa de um país podem ser analisados segundo uma lógica de 'círculos concêntricos': interno, regional e internacional, sendo que estes se interligam e influenciam mutuamente. Esta grelha é particularmente útil para discutir a evolução da política externa nigeriana (Adebajo e Mustapha, 2008) desde a sua independência. No círculo interno, destaca-se a estabilidade económica e política como fatores de sustentação de uma política externa vigorosa e empenhada. Ao nível regional, distinguem-se as relações no âmbito de uma vizinhança mais próxima (Chade, Camarões, Níger e Benim) e de uma vizinhança alargada (Angola ou África do Sul), tendo esta um impacto direto na projeção in-

99 Ver capítulo teórico neste Manual, secção "Compreender a política externa". 
ternacional do continente africano. Salienta-se ainda o papel das organizações regionais na afirmação da política externa nigeriana. $\mathrm{O}$ círculo internacional inclui as dinâmicas de participação em organizações internacionais, nomeadamente de natureza multilateral, bem como as relações com outros países, nomeadamente com potências internacionais e regionais. É importante referir que a intensidade da influência de cada um destes círculos na formulação da política externa se foi alterando ao longo dos anos e de acordo com as linhas de atuação externa de cada regime.

Acresce ainda, que em 1960, a Nigéria encontrava-se numa posição privilegiada para assumir esta liderança: país independente, rico e com uma posição claramente definida a favor dos movimentos de libertação nacional. Esta luta contra o domínio colonial em África, bem como contra o apartheid na África do Sul, domina a política externa nigeriana até à década de 1980 (círculo regional). A exploração da sua riqueza petrolífera permitiu, principalmente na década de 1970, uma política externa assertiva, nomeadamente no plano regional (círculos interno e regional). Este percurso de afirmação da liderança regional perdeu fôlego na primeira metade da década de 1980, devido à alteração do regime interno, à queda do preço do petróleo e às pressões da dívida externa. No final da década de 1980, assiste-se a uma reafirmação da imagem externa nigeriana no continente africano, permitindo projetar-se internacionalmente. Esta projeção internacional, por sua vez, consolidou a sua posição regional. Este período caracterizou-se assim por uma interdependência entre a liderança regional e o papel internacional da Nigéria (círculos regional e internacional).

A política externa nigeriana da década de 1990 ficou marcada pelo regime militar violento de Abacha (1993-1998), influenciando de forma devastadora a imagem externa da Nigéria (círculo interno). Com a transição democrática, a Nigéria ganha uma nova oportunidade para retomar o seu 'destino' de líder africano negro. No entanto, 
as mudanças profundas nas conjunturas regional e internacional limitaram de forma estrutural a capacidade da Nigéria concretizar o seu papel de liderança. Além disso, internamente, a qualidade da democracia tem-se revelado frágil e marcada pela corrupção e clientelismo generalizados, bem como, em particular nos últimos anos, pela violência alimentada pelo movimento fundamentalista islâmico Boko Haram ${ }^{100}$ (círculo interno). A Nigéria não abandona o seu sentido de responsabilidade regional, mas passa a privilegiar canais multilaterais para cumprir esse objetivo, nomeadamente através de missões de paz das Nações Unidas (círculo internacional). Regionalmente, a política externa nigeriana tem-se pautado por iniciativas de soft power, incluindo mediação de conflitos e promoção da integração económica regional (círculo regional).

\section{Dimensão interna}

Internamente, a Nigéria desde cedo se deparou com os inúmeros desafios colocados pela imensa e indiscutível diversidade étnica: cerca de 250 grupos étnicos com predominância de Hausa e Fulani (29\%), Yoruba (21\%) e Igbo (18\%); e religiosa: população maioritariamente muçulmana (50\%) e cristã $(40 \%)^{101}$. Esta diversidade interna foi-se interligando com outros elementos, nomeadamente com os recursos naturais, sobretudo o petróleo, refletindo-se em problemas

100 O movimento Boko Haram é um grupo fundamentalista islâmico criado em 2001 por Mohammed Yusuf que se apresenta como radicalmente oposto às influências ocidentais e defende a islamização do país através da imposição da lei islâmica. Começou com uma base operacional inicialmente restrita à região nordeste do país, mas rapidamente se foi ampliando a outras regiões, tanto do ponto de vista da sua base de recrutamento como da condução de ataques violentos contra a população civil (Simon, 2014).

101 Informação disponível na página da Freedom House, no relatório sobre Freedom of the Press, Nigeria (2006). [www.freedomhouse.org/template.cfm? page= $251 \&$ country=7030\&year $=2006$ ] (consultado a 14 de março de 2015). 
de distribuição dos recursos e dos rendimentos geradores de tensões constantes entre o sul produtor e o norte mais populoso. Todas estas questões acabaram por se refletir naquela que foi sendo a evolução, nem sempre linear, da política externa nigeriana.

A este nível interno, e ainda que com estratégias e capacidades variáveis e distintas, a Nigéria pautou sempre a sua política externa pela ideia de que um país económica e politicamente estável e com uma qualidade de vida satisfatória está melhor posicionado para desenvolver uma política externa assertiva. Os princípios orientadores da política externa nigeriana, finalmente plasmados na Constituição de 1979, passavam, em grande medida, pela «defesa da integridade territorial e da independência do país", pela promoção do desenvolvimento económico nacional autónomo e sustentável, pela "promoção da igualdade e autossubsistência em África, respeitando a dignidade humana, especialmente para a população negra, bem como [pel]a promoção e defesa da paz mundial» (Ajibewa, 1998: 86).

Imediatamente após a independência (1960), a política externa nigeriana durante a primeira república liderada por Balewa (1960-1966) foi caracterizada como "conservadora e tímida" (Abegunrin, 2001: 105) e "sem visão" (Garuba, 2008: 2). Na verdade, o legado colonial, a relativa pobreza do país, a personalidade conservadora de Balewa e a falta de experiência no plano internacional ajudam a explicar esta falta de autonomia e iniciativa em assuntos internacionais. Por exemplo, alguns autores referem que no que diz respeito a questões centrais para África, Balewa parecia estar sempre à espera da tomada de posição de outros países antes de afirmar a posição nigeriana (Garuba, 2008: 2).

Acresce ainda que a estrutura federal colonial do país criou a possibilidade, neste período, de cada estado-federado abrir a sua própria representação diplomática no estrangeiro, o que ilustra o caráter limitado da política externa nigeriana (Abegunrin, 2001: 105-106). Ainda assim, Balewa criou uma estrutura de tomada de decisão 
em matéria de política externa com vários ministérios e gabinetes ao nível federal. No entanto, a sua postura centralizadora, aliada a uma incapacidade de coordenação das distintas instituições, determinou não só a centralidade do cargo de chefe de estado, que neste caso, chegou a acumular a pasta de Ministro dos Negócios Estrangeiros (Inamete, 2001: 33), mas também a incapacidade das instituições criadas exercerem as suas funções de forma autónoma e ativa.

Apesar de a Nigéria ter sido governada predominantemente por regimes militares entre 1966 e 1999, é importante distinguir a fase pré e pós 1979, por dois motivos. O primeiro prende-se com a proclamação da segunda república constitucional entre 1979 e 1983 que criou as condições para uma maior abertura política, que só foi posta em causa com o regime de Abacha (1993-1998). O segundo está relacionado com a riqueza resultante de recursos petrolíferos que permitiu à Nigéria concretizar os seus objetivos de política externa de forma assertiva e autónoma até 1979. A partir desta data, esta capacidade de concretização da política externa nigeriana diminuiu significativamente, devido à crise petrolífera, à crise da dívida e à corrupção interna e desvio de fundos. Convém ainda referir, que dentro destas duas fases existem também diferenças marcantes entre os vários regimes.

Em 1966, dão-se os primeiros de vários golpes militares que marcam estruturalmente a vida política da Nigéria, influenciando diretamente a sua política externa. O regime militar de Gowon (1966-1975), assim como a sua política externa, são profundamente marcados pela guerra civil no Biafra (região secessionista). Internamente, o regime teve dificuldade em reagir de forma rápida e eficaz aos sinais que desencadearam a violência e as estruturas do Ministério dos Negócios Estrangeiros mostraram-se desadequadas para lidar com a magnitude da crise. Gowon viu-se mesmo obrigado a enviar equipas especiais para explicar internacionalmente a posição do governo federal nesta matéria (Garuba, 2008). A guerra civil ditou 
uma viragem na definição da política externa nigeriana, passando-se de uma abordagem conservadora e tímida para uma abordagem assertiva, defendendo a sua integridade territorial. A Nigéria ganhou assim uma imagem pública de uma nação africana ativa e rica em petróleo.

Um novo golpe militar em 1975 coloca no poder Mohammed/ Obasanjo (1975-1979). Contrariamente aos anteriores, este período é caracterizado por uma política externa robusta, assertiva, dinâmica e, muitas vezes, denominada de radical. Os 'anos de ouro' da política externa nigeriana foram maioritariamente financiados pelos rendimentos provenientes do petróleo, permitindo uma abordagem autónoma e pró-ativa. A formulação e implementação desta nova abordagem foram ainda potenciadas pela reforma das estruturas internas de tomada de decisão de política externa que passaram a incluir atores da sociedade civil ${ }^{102}$ (Abegunrin, 2001: 110).

Simultaneamente, quer Mohammed, quer Obasanjo mostraram-se empenhados em utilizar os militares na persecução dos objetivos nigerianos de política externa (Inamete, 2001: 88). Esta posição é particularmente visível na decisão de enviar delegações militares a Angola, reconhecendo o governo do Movimento Popular de Libertação de Angola (MPLA), sem o aval desse Ministério (Inamete, 2001: 88). A nacionalização da British Petrol e do Barcklays Bank, transformando-os em African Petrol e em Union Bank of Nigeria (Garuba, 2008: 7), respetivamente, ilustram igualmente a determinação nigeriana em se afirmar como uma potência autónoma e independente.

A segunda república nigeriana debateu-se com a diminuição da riqueza disponível para continuar a financiar a linha de política

102 Nomeadamente através da criação do Instituto Nigeriano de Relações Internacionais e do Instituto Nacional para Política e Estudos Estratégicos (Abegunrin, 2001: 110). 
externa interventiva e autónoma dos regimes anteriores. Apesar da aprovação de uma constituição e da possibilidade de realização de eleições, com o fim dos dividendos das crises petrolíferas, o governo Shagari (1979-1983) viu-se obrigado a adotar uma postura mais moderada e pró-ocidental. A situação económica degradada e a crescente dívida externa do país justificaram o golpe de estado que coloca Buhari (1983-1985) no poder. A sua política externa foi caracterizada como agressiva e nacionalista, mas menos ambiciosa e com menos apoio interno que a do regime anterior. Identificando a corrupção generalizada no país como um problema estrutural, Buhari decretou 'Guerra Contra a Indisciplina' e a corrupção, apesar de estes esforços não terem sido suficientes para resolver os problemas internos (Abegunrin, 2003: 131). Os métodos aplicados por este regime, bem como o aprofundar da crise económica, criaram um descontentamento crescente no seio da população, o que propiciou as condições para um novo golpe de estado em 1985, que coloca Babangida (1985-1993) no poder.

A política externa de Babangida refletiu a confusão e turbulência política interna, tendo o Ministro dos Negócios Estrangeiros sido substituído cinco vezes ao longo deste regime (Abegunrin, 2001: 120). No sentido de dar consistência aos compromissos assumidos internacionalmente, Babangida criou o Corpo de Assistência Técnica no âmbito do Ministério dos Negócios Estrangeiros para dar apoio aos países africanos, das Caraíbas e do Pacífico. O descontentamento interno identificado durante o regime Buhari manteve-se, acrescido pela perceção de que os recursos utilizados para concretizar a política externa nigeriana - missões de paz, apoios financeiros a países vizinhos, fundos de desenvolvimento regional, entre outros - estavam a ser desperdiçados e/ou indevidamente apropriados. Babangida tentou responder a estas críticas, lançando um debate nacional sobre a posição nigeriana relativamente à dívida externa e à relação com o Fundo Monetário Internacional e realizando 
uma conferência pública sobre política externa, numa tentativa de demonstrar abertura e transparência nesta matéria (Garuba, 2008: 9). A crise económica, no entanto, dificultou estruturalmente a capacidade da Nigéria assumir as suas responsabilidades internas e externas (Garuba, 2008: 9).

O ano de 1993, apesar de marcado por vários acontecimentos importantes - anulação das eleições para a terceira república, nomeação de um novo chefe de estado (Shonekan) e novo golpe de estado - não permitiu qualquer revisão da política externa nigeriana. O regime subsequente, liderado por Abacha (1993-1998), tomou o poder disposto a controlar a situação económica e o descontentamento interno por qualquer meio ao seu dispor. Assim, este revela-se o regime mais agressivo e opressivo da história da Nigéria, contendo grupos da oposição interna com 'mão de ferro', como ilustra a condenação a prisão perpétua em 1994 de Obasanjo e Yar'Adua (Abegunrin, 2001: 126-127) e a execução em 1995 de nove ativistas Ogoni. Neste seguimento, a Nigéria foi suspensa da Commonwealth of Nations e condenada pela Assembleia Geral das Nações Unidas por alegadas violações de direitos humanos. Na verdade, durante o regime de Abacha, a sua política externa foi essencialmente condicionada pelas reações internacionais à situação interna.

Em 1998, Abacha morre e Abubakar (1998-1999) sobe ao poder, abrindo um novo capítulo na história política do país. De facto, a morte de Abacha foi vista como uma oportunidade para «intensificar as pressões para o regime libertar todos os prisioneiros políticos, desmilitarizar a política nigeriana, e transferir o poder para um governo civil eleito" (Abegunrin, 2003: 163), procurando contrariar a imagem negativa deixada pelo regime anterior. Num gesto claro de concretização do plano estabelecido, Abubakar liberta os prisioneiros políticos, incluindo Obasanjo, o que "constituiu um passo importante para o recuperar da credibilidade internacional da Nigéria depois de anos de isolacionismo diplomático» (Abegunrin, 2003: 163). Em 1999, 
Abubakar passa o poder para um governo civil eleito liderado por Obasanjo (1999-2003 e 2003-2007), acabando com 15 anos de regime militar. "Com esta ação, Abubakar salvou os militares nigerianos de si próprios e restaurou o direito democrático do povo nigeriano de escolher o seu próprio governo" (Abegunrin, 2003: 164).

A eleição de Obasanjo em 1999 inaugura a quarta república nigeriana que se caracterizou por um compromisso com a consolidação da democracia, respeito pelos direitos humanos, reformas económicas liberais, bem como boa governação e transparência. Este compromisso espelha a ambição da Nigéria em se consolidar internamente e em se integrar de forma estável no sistema internacional. Após dois mandatos, Obasanjo é substituído por Yar'Adua (2007-2010) cujo objetivo principal era transformar a Nigéria numa das vinte maiores economias do mundo até 2020 (Garuba, 2008: 17). Uma das características essenciais da sua política externa foi o fomento da participação interna na sua formulação e definição 'diplomacia de cidadania' - procurando contrariar a imagem de um país corrupto.

Do ponto de vista da estabilidade e qualidade democráticas da Nigéria, apesar da última década ter sido caracterizada por transições de poder civis e com recurso a eleições, estas têm sido consideradas como "um circo" (Obasanjo em 1999), como irregulares e manipuladas (Obasanjo em 2003), e como uma «fraude» e fantochada (Yar'Adua em 2007) (Taylor, 2007). De referir ainda que a morte de Yar'Adua levou a uma transição pacífica do poder para o Vice-Presidente, Goodluck Jonathan (2010-2011). Em 2011, ganhou as suas primeiras eleições para Presidente, apesar das acusações de fraude (2011-2015). A política externa do governo de Jonathan enfrentou como principais desafios de política interna: a corrupção e a gestão dos conflitos internos violentos, nomeadamente nas zonas de exploração petrolífera. As relações clientelares, patrimonialistas e corruptas sustentam a economia política nigeriana, envolvendo os 
atores de investimento direto estrangeiro nesta dinâmica e criando uma elite cada vez mais rica e poderosa ao nível das decisões estratégicas do país. A criação de 'economias enclave' em torno do petróleo agrava os desequilíbrios internos, alimentando dinâmicas de greed and grievance. Estas dinâmicas têm gerado focos de violência e instabilidade que minam não só a relação da Nigéria com os seus parceiros na exploração petrolífera (como por exemplo no Delta do Níger), como a sua própria estabilidade interna, enfraquecendo a sua capacidade de projeção internacional.

É fundamental destacar ainda, nesta dimensão interna, uma dinâmica de violência que emerge em 2009, mas que a partir de 2010 ganha importância central na vida política da Nigéria, repercutindo-se também a nível da imagem e política externa do país. O movimento rebelde islamita do Boko Haram contesta abertamente o poder político de Jonathan, acusando-o de corrupto e pró-ocidental, e procura impor um modelo radical da lei islâmica no Norte da Nigéria. Ataques sistemáticos a forças militares e policiais, mas também a civis, em particular cristãos e muçulmanos que cooperam com o governo e se opõem ao grupo radical (Human Rights Watch, 2013) alteraram a dinâmica de política interna nigeriana. Os ataques levados a cabo e reivindicados pelo movimento Boko Haram têm-se sucedido e agravado $^{103}$, num braço de ferro em que o governo nigeriano nem sempre tem sabido ganhar, e com consequências negativas tanto do ponto de vista da imagem interna (visto como incapaz de garantir a estabilidade e segurança da população) como externa (com a sua imagem de líder regional claramente posta em causa). Em particular, o rapto de 276 raparigas em abril de 2014 determinou importantes críticas internas e internacionais ao governo nigeriano, em virtude

103 De acordo com vários relatórios, estima-se que nos últimos 5 anos, o movimento Boko Haram tenha sido responsável pela morte de mais de 10.000 pessoas em ataques indiscriminados contra a população civil e forças policiais e/ou militares (Aljazeera, 2014). 
da resposta tardia e pouco robusta. Esta demonstração de uma certa incapacidade por parte do governo em garantir condições de segurança dentro do seu território, deu força ao movimento que, desde meados de 2014, conseguiu o controlo de uma parte significativa do território - equivalente à dimensão da Bélgica - em particular na região de Borno (Simon, 2014; Dersso, 2015). Relativamente a esta questão, existem várias leituras em torno das razões para a origem do Boko Haram. Uma delas, e particularmente importante para esta dimensão, é a que se refere ao movimento radical como um instrumento da oligarquia do norte da Nigéria usado contra a presidência de Goodluck Jonathan e por este, enquanto originário do Sul, se ter 'atrevido' a ocupar o lugar quando seria a vez do Norte. Com esta estratégia, grupos do Norte e opositores do Presidente conseguiriam (e, de certa forma conseguiram) contribuir para uma ideia do país como ingovernável e responsabilizar Jonathan por esse resultado (Dersso, 2014).

O resultado das eleições de 28 de março de 2015, que deu a vitória ao candidato da oposição General Muhammadu Buhari, reflete claramente uma vida política nigeriana em transição. Pela primeira vez na história nigeriana, um Presidente incumbente perde as eleições. Acresce ainda que o novo Presidente já tinha sido Presidente entre 1984 e 1985, após um golpe de estado. E, quando muitos esperavam que Goodluck Jonathan não cedesse o cargo facilmente, este, após a divulgação dos resultados, telefonou ao seu opositor dando-lhe os parabéns. Todas estas dinâmicas são novas para a Nigéria.

A BBC identifica cinco razões que explicam a perda das eleições por Goodluck Jonathan: o processo eleitoral tornou-se mais competitivo e portanto mais difícil de cometer fraude eleitoral; a primazia do Partido Democrático do Povo, no poder desde 1999, foi ultrapassada pelo Congresso de Todos os Progressistas que uniu toda a oposição; uma grande percentagem da população continua 
sem beneficiar do crescimento económico do país, com metade da população a viver abaixo do limiar mínimo de pobreza; a questão da segurança interna e a violência do Boko Haram determinou duras críticas a Jonathan; e, finalmente, muitos têm simplesmente defendido que é hora de mudar (Zane, 2015).

\section{Dimensão regional}

A ideia de liderança do continente africano que sempre esteve na base da definição do papel da Nigéria no sistema internacional é mais saliente a nível regional. Não só a população nigeriana acredita "que o seu país é uma superpotência (...) [e] que com uma melhor liderança, a Nigéria rapidamente se tornará o farol para África»104, como internacionalmente a Nigéria foi sendo reconhecida como o "equivalente para África do Brasil, Índia, ou Indonésia» (Maier, 2000). Neste sentido, a Nigéria desenvolveu esforços em diferentes planos, ao longo do tempo, e com resultados distintos. A sua política externa regional tem sido pautada pela promoção do desenvolvimento e estabilidade regionais, com o intuito de consolidar uma arquitetura de paz africana, a qual tem sido denominada de Pax Nigeriana (Adebajo and Mustapha, 2008; Nuamah, 2003; Pham, 2007: 14). Esta abordagem tem incluído projetos de integração e afirmação económica, como a Economic Community of West African States (ECOWAS) ou a New Economic Partnership for Africa's Development (NEPAD); apoio político e financeiro aos movimentos de descolonização em África e contra o apartheid, por exemplo denominando-se membro honorário dos 'Estados da Linha da Frente'105; e através do apoio e

104 Informação constante do Suplemento Especial do The Economist, "Here's Hoping: A Survey of Nigeria" de 15 de janeiro de 2000.

105 Os «Estados da Linha Frente» são um grupo regional de estados do sul de África que se organizaram contra o regime do apartheid e a favor da democracia. 
promoção de estruturas no seio de organizações africanas e missões de paz, como na Libéria e Serra Leoa.

O papel de líder regional tão ambicionado pela Nigéria, durante o governo Balewa (1960-1966), ficou limitado pela ausência de iniciativa própria e pelo conservadorismo que caracterizava a política externa nigeriana nestes primeiros anos de independência. Ainda assim, Balewa considerou essencial que a Nigéria adotasse e respeitasse os princípios de direito internacional - não-interferência, integridade territorial e boa vizinhança - como se esperava de um jovem país independente. E, para este efeito, contribuiu para a criação da Organização de Unidade Africana (OUA) e desenvolveu «estruturas institucionais para a exploração de recursos naturais transnacionais para desenvolvimento económico»106 (Nuamah, 2003: 11).

Durante a primeira fase dos regimes militares (1966-1979), a dimensão regional da política externa nigeriana sofreu «transformações dramáticas” (Abegunrin, 2001: 109), não tanto por passar a haver uma coerência ou estratégia deliberada, mas antes por existirem meios disponíveis, devido à exploração petrolífera, para ir apoiando determinadas posições. Os dividendos petrolíferos permitiram uma política mais assertiva no que diz respeito à luta contra o apartheid na África do Sul e à concessão de assistência bilateral a movimentos de libertação nacional (na Rodésia e em Angola) - 'diplomacia spray'. Esta estratégia material foi sendo acompanhada por uma posição política firme. Por exemplo, durante o curto governo de Ironsi (1966), o espaço aéreo nigeriano foi fechado aos voos de e para a África do Sul, como forma de fazer pressão sobre o regime de apartheid, e a Embaixada Portuguesa em Lagos foi encerrada,

O grupo foi criado em 1970, contando com Angola, Botswana, Lesotho, Moçambique, Suazilândia, Tanzânia, Zâmbia, e desde 1980, Zimbabué.

106 Como é ilustrado pela criação da Comissão da Bacia do Rio Níger (1973) e as subsequentes comissões bilaterais Nigéria-Benin e Nigéria-Níger (Nuamah, 2003: 11). 
como forma de protesto contra o domínio colonial português em África. Através destas medidas, a Nigéria assumiu o seu papel como "líder negro e africano» (Abegunrin, 2001: 109).

A política externa do regime de Gowon (1966-1975) foi marcada pela guerra civil, opondo-o aos secessionistas no Biafra. A guerra civil levou o governo nigeriano a adotar uma postura mais ativa e envolvida com os seus vizinhos (Nuamah, 2003), nomeadamente no que diz respeito ao apoio concedido aos secessionistas por alguns destes. Este maior envolvimento regional ganhou fôlego com os meios disponíveis devido ao boom petrolífero, permitindo uma política regional e africana vigorosa. Esta estratégia culminou com a criação da ECOWAS em 1975, promovendo a integração e cooperação regionais.

O regime de Mohammed/Obasanjo (1975-1979) foi o que mais utilizou os meios económicos, resultantes da riqueza petrolífera para a concretização de políticas radicais e assertivas em matéria de política externa. Nesse sentido, apostou no apoio financeiro, material e técnico bilateral a vários países africanos: assistência a países recém-independentes (Moçambique, Cabo Verde e Zimbabwe); apoio humanitário a países assolados por catástrofes naturais (seca na Etiópia); assistência técnica a diferentes países (Argélia e Gâmbia); concessão de bolsas a estudantes africanos; e venda de petróleo a preços reduzidos a alguns países africanos mais necessitados (e não a outros). Estes apoios não eram inéditos, mas adquiriram uma dimensão pujante durante este regime. A assistência financeira passou a fazer parte integral da política externa nigeriana, sendo inclusivamente institucionalizada com a criação do Fundo Nigeriano no âmbito do Banco Africano para o Desenvolvimento. Esta lógica de apoio económico bilateral e regional baseia-se na convicção que a estabilidade e desenvolvimento económico dos países africanos contribuem para a estabilidade e desenvolvimento da Nigéria; e, desta forma, uma Nigéria estável e rica deve apoiar 
os países vizinhos nesse sentido. Assim, a Nigéria empenhou-se em "criar, promover e acelerar a integração económica entre os países africanos da África Ocidental, nomeadamente através da ECOWAS» (Inamete, 2001: 89-90).

Estes esforços económicos foram acompanhados por uma estratégia política de envolvimento e liderança no continente africano. O reconhecimento do governo angolano do MPLA constituiu um elemento fundamental de mudança na imagem da Nigéria, enquanto líder regional e continental. Com esta decisão, não só tomou uma posição contrária à dos Estados Unidos da América (EUA); como se empenhou na mobilização de países africanos para que estes também reconhecessem o novo governo angolano. Desta forma, a Nigéria passou a ser reconhecida como um "membro de facto dos 'Estados da Linha da Frente', insistindo no direito de ser consultada como tal» (Abegunrin, 2001: 114, itálico no original).

Estes esforços continuaram durante o regime militar de Mohammed/Obasanjo (1975-1979), mantendo, de forma robusta, o lugar central que o continente africano tinha na política externa nigeriana. No entanto, o governo seguinte liderado por Shagari (1979-1983) protagonizou um revés na estratégia de afirmação da Nigéria em África. Três acontecimentos em particular marcaram esta mudança drástica: os confrontos com os Camarões, a situação no Chade e a política interna de imigração. A Nigéria não conseguiu conter os conflitos violentos na fronteira com os Camarões (Península de Bakassi), acabando por ter de pedir ajuda à então OUA para intervir (Ajibewa, 1998). No caso do Chade, considerado o "pior reverso diplomático da Nigéria" (Ajibewa, 1998), Shagari "foi acusado de servir como uma nação mercenária 'para proteger os interesses dos EUA'” (Ajibewa, 1998: 89). O envio de forças armadas nigerianas para participar na missão da OUA no Chade foi interpretado por vários como um apoio à "intervenção imperialista americana" (Ajibewa, 1998: 89). Finalmente, em 1983, Shagari expulsou milhões 
de trabalhadores migrantes do Gana, Chade e Benim, contrariando os princípios da ECOWAS e fechando as fronteiras com o Benim e o Níger. Todas estas decisões contribuíram para um denegrir da imagem de liderança da Nigéria em África, transmitindo uma imagem pouco assertiva, sem iniciativa própria e sem capacidade de afirmação.

Entre 1984 e 1998, a Nigéria entra na segunda fase dos regimes militares. Os regimes de Buhari (1984-1985) e Babangida (1985-1993) desenvolveram esforços no sentido de recuperar a imagem de liderança da Nigéria e de reafirmar a centralidade africana na sua política externa. Apesar do seu curto mandato, Buhari (1984-1985) realizou um périplo pelos 'Estados da Linha da Frente' - 'diplomacia vai-e-vem' -, reafirmando o compromisso da Nigéria com os movimentos de libertação; reconheceu a Frente Polisario como governo legítimo do Sahara Ocidental; e fez uma demonstração de força ao colocar as forças armadas nas fronteiras com o Chade e os Camarões.

O regime de Babangida (1985-1993) tomou o poder empenhado em desenvolver uma política externa dinâmica e coerente, ancorada no papel central das organizações regionais (OUA e ECOWAS) e no princípio de boa vizinhança. Um dos reflexos desta vontade política foi a Doutrina Akinyemi ${ }^{107}$ onde se afirmava que «para obter o apoio político, diplomático ou outro da Nigéria, a Nigéria [devia] ser primeiro consultada por outros estados africanos antes dos mesmos tomarem alguma ação significativa de política externa" (Ihonvbere, 1994: 50). Ao nível das organizações regionais, Babangida encetou esforços para reativar a ECOWAS, garantindo o seu financiamento e secretariado, organizando três cimeiras de chefes de estado e de governo e presidindo à organização quando nenhum outro membro se mostrou interessado. Estas medidas mostram claramente como o ob-

107 Akinyemi foi um dos Ministros dos Negócios Estrangeiros do regime do Babangida. 
jetivo de estabilização da região através da ECOWAS se manteve central para a afirmação política e económica da Nigéria a nível regional.

Em 1993, no âmbito da ECOWAS, a criação do Economic Community of West African States Monitoring Group (ECOMOG) para a Libéria (1990-1998), constituiu uma das iniciativas mais assertivas da política externa nigeriana no pós-Guerra Fria. O envolvimento militar da Nigéria no ECOMOG resultou em parte da existência de relações privilegiadas entre os chefes de estado dos dois países e da preocupação em zelar pela estabilidade regional em resposta a um alegado plano de desestabilização líbio (Abegunrin, 2001: 121). A OUA manteve-se igualmente o fórum privilegiado de atuação regional da Nigéria, tendo Babangida presidido à organização em 1991, mediando vários conflitos armados, nomeadamente no Uganda e em Angola, e criando um Departamento de Prevenção, Gestão e Resolução de Conflitos. Durante este período, a Nigéria manteve também o seu estatuto de membro honorário dos 'Estados da Linha da Frente', continuando a apoiar os movimentos de libertação na África do Sul e na Namíbia (Abegunrin, 2001; Ihonvbere, 1994). Um outro acontecimento que marcou a política externa nigeriana de Babangida foi a visita do seu homólogo sul-africano, De Klerk, em 1992. Esta visita tem sido entendida, por alguns, como uma contradição da política nigeriana de luta contra o apartheid (Garuba, 2008: 10); enquanto para outros, a visita constituiu um reconhecimento do prestígio da Nigéria, ao ser incluída no périplo de De Klerk (Abegunrin, 2001: 122).

O regime violento de Abacha (1993-1998) procurou manter o seu envolvimento na procura da estabilidade regional e na defesa da sua integridade territorial. No primeiro caso, mantendo a sua participação no ECOMOG na Libéria e iniciando uma nova missão na Serra Leoa (1997-2000). No segundo caso, a Nigéria envolveu-se em confrontos fronteiriços, opondo o seu exército ao dos Camarões, devido ainda à disputa sobre a Península de Bakassi, mostrando a sua determinação 
em fazer valer a sua posição de forma assertiva (Abegunrin, 2001: 126). No entanto, a violência e agressividade do regime em conter as atividades da oposição interna afetaram de forma determinante as relações da Nigéria com os países africanos. Em particular com a África do Sul, a qual manteve «uma política de porta aberta relativamente aos opositores do regime de Abacha, especialmente aos grupos pró-democráticos» (Abegunrin, 2001: 126-127). As relações entre os dois países atingiram o seu nível mais baixo, após a morte dos nove ativistas Ogoni em 1995, o que "Mandela considerou um golpe pessoal, pois tinha recebido garantias que estes ativistas não seriam mortos» (Abegunrin, 2001: 127).

Com o governo de Abubakar (1998-1999), o processo de recuperação da imagem externa da Nigéria, após o isolamento diplomático a que tinha sido remetida durante o regime de Abacha, ganha novo ímpeto. No entanto, contrariando a lógica até agora subjacente ao seu papel regional, Abubakar recusou participar no ECOMOG para a Guiné-Bissau e iniciou a retirada das forças armadas nigerianas destacadas na Serra Leoa (Pham, 2007: 13). O falhanço da missão da ECOWAS na Guiné-Bissau levou a que vários analistas considerassem a Nigéria como um elemento indispensável para qualquer esforço de paz na região (Nuamah, 2003).

Com a eleição dos dois governos consecutivos de Obasanjo (1999-2007), assistiu-se a um reforço da diminuição do envolvimento militar nigeriano nos esforços regionais de paz ${ }^{108}$, com a continuação da retirada do ECOMOG da Serra Leoa. O regime de Obasanjo passou a privilegiar regionalmente o soft power através da mediação de conflitos armados, por exemplo no Sudão, no Togo ou no Senegal, e da criação de mecanismos institucionais para responder a situações de crise, como o Mecanismo para Prevenção, Gestão, Resolução de

108 O envolvimento internacional nos esforços de paz regional será abordado na secção seguinte. 
Conflitos, Peacekeeping e Segurança, criado em 1999 no âmbito da ECOWAS. No que diz respeito aos seus vizinhos, a disputa com os Camarões sobre a Península de Bakassi fica marcada pela decisão do Tribunal Internacional de Justiça (2002) favorável aos Camarões. Do ponto de vista do objetivo de integração económica, durante os mandatos de Obasanjo, destaca-se ainda o Projeto do Gasoduto da África Ocidental que integra o Benim, o Gana e o Togo. O projeto sofreu diversos atrasados, tendo iniciado as suas funções em pleno em dezembro de 2008.

Na sua dimensão regional é clara a centralidade da ECOWAS para a política externa nigeriana. A Nigéria esteve envolvida na sua criação, manutenção, funcionamento, alargamento de funções, quer com recursos financeiros, quer humanos. No entanto, a estabilidade com base no desenvolvimento económico ambicionada pela Nigéria para si e para os seus vizinhos não tem sido alcançada. Por exemplo, os esforços da Nigéria em prol da integração regional têm sido, paradoxalmente, postos em causa pelo seu papel dominante no aumento do comércio informal transfronteiriço (Nuamah, 2003: 12). Ainda assim, a ECOWAS tem funcionado como um fórum político importante onde é valorizado o consenso regional (Pham, 2007: 11-12), no âmbito da qual a Nigéria tem tido um papel fundamental. Do ponto de vista dos esforços regionais de paz no âmbito da ECOWAS, alguns analistas avançam um papel de 'polícia regional' para caracterizar o envolvimento da Nigéria. Mas o facto de em anos recentes a Nigéria ter retirado forças armadas do ECOMOG da Serra Leoa e ter recusado participar no da Guiné-Bissau contraria esta ideia. A Nigéria, na verdade, parece ter optado por ativar regionalmente o seu soft power em detrimento de uma política assertiva mais militarizada, a qual passa a ser assegurada na região através de canais multilaterais. Independentemente dos meios utilizados, a sua presença é reconhecida como indispensável para o sucesso de quaisquer iniciativas de paz regional (Adebajo, 2002). 
Com a Presidência de Goodluck Jonathan, a Nigéria assumiu-se como ator importante na arquitetura de paz e segurança em África, tendo presidido ao Conselho de Paz e Segurança da União Africana em abril de 2014 e participado em algumas missões de paz das Nações Unidas em África, com particular destaque para a MINUSMA, no Mali, liderada pela França e criada em julho de 2013, para responder à instabilidade política e militar e para a qual contribuiu inicialmente com cerca de 1200 efetivos militares (BBC, 2013). Contudo, e em virtude da instabilidade e violência causadas pelos ataques do Boko Haram, a Nigéria viu-se obrigada a retirar, poucos meses depois, parte das suas tropas do Mali (e do Darfur) para as concentrar na estratégia de combate ao grupo islâmico dentro do seu próprio território, claramente redefinindo as suas prioridades em termos de segurança (da dimensão regional para a dimensão interna) (McGregor, 2013).

Nos últimos anos, o potencial de liderança regional da Nigéria tem diminuído face à afirmação de uma África do Sul multirracial, democrática e com uma economia emergente, a qual surge em melhor posição para reclamar a liderança africana do que uma Nigéria caracterizada por conflitos violentos internos e minada pela corrupção. Ainda assim, as relações com a África do Sul melhoraram substancialmente durante o regime de Obasanjo, falando-se mesmo de "uma aliança estratégica em evolução" (Nuamah, 2003: 13), a qual se refletiu, nomeadamente, nos esforços de consolidação da União Africana (UA) e de criação do NEPAD, como resposta à crise de desenvolvimento do continente africano. Esta colaboração manifestou-se também na posição conjunta contra a criação de um comando militar dos EUA em África (AFRICOM) ${ }^{109}$.

109 De referir que Yar'Adua (2007-2010) concedeu o perdão de cerca de 30\% da dívida externa liberiana para com a Nigéria, como recompensa por esta se ter negado a acolher a sede do AFRICOM (Garuba, 2008). 
No entanto, desde a presidência de Obasanjo que a rivalidade entre a Nigéria e a África do Sul se tem tornado mais visível, nomeadamente no que diz respeito à crise na Líbia (2011) e à eleição do Presidente da União Africana em 2012 (Agbu et al, 2013). Durante a crise na Líbia, a União Africana criou uma comissão ad hoc para desenvolver esforços no sentido de se encontrar uma solução para a crise. A Nigéria não foi incluída nesta comissão e o Presidente da África do Sul, Jacob Zuma, encabeçou os esforços desenvolvidos, o que the conferiu uma maior visibilidade como líder do continente africano. A Nigéria, no entanto, rapidamente reconheceu o Conselho de Transição Nacional na Líbia de forma unilateral, antes de haver uma posição da UA, tendo sido duramente criticada pelo Presidente Zuma (Agbu et al, 2013: 9). Apesar deste protesto, é importante salientar que a posição nigeriana acabou por prevalecer e posteriormente se tornou a resposta oficial da União Africana (Agbu et al, 2013: 9). A eleição do Presidente da Comissão da União Africana constituiu outro momento em que a tensão entre os dois países se tornou saliente. Desde os tempos da Organização de Unidade Africana que existia um compromisso verbal entre os cinco maiores contribuintes financeiros - Argélia, Egito, Líbia, Nigéria e África do Sul - para não concorrerem nem ocuparem o lugar de Presidente da Comissão da União Africana. Em 2012, a África do Sul, com o apoio dos países membros da Comunidade para o Desenvolvimento da África Austral (SADC), candidatou-se e ganhou as eleições contra o candidato incumbente apoiado pela Nigéria e pelos países membros da ECOWAS. A eleição de Dlamini Zuma tem sido considerada vantajosa para as aspirações sul-africanas de obter um lugar no Conselho de Segurança das Nações Unidas (Agbu et al, 2013: 10).

A construção de uma Pax Nigeriana tem, como demonstrado, sido pautada por uma afirmação ora económica, ora político-militar, nem sempre conseguida. De facto, a predominância regional natural da Nigéria tem contribuído para criar um contexto propício a uma 
política externa influente e, por vezes, assertiva, mas também tem sido frequentemente caracterizada por avanços e recuos estruturais acompanhando claramente as mudanças de regime interno. Assim, o 'destino' nigeriano mantém-se um potencial reconhecido, mas ainda por concretizar. E, atualmente, "tendo em conta a realidade dos atuais equilíbrios de poder [em África], a liderança nigeriana tem de ser articulada com outras potências económicas e políticas da região, incluindo a África do Sul» (Pham, 2007: 16).

Com a Primavera Árabe, a política externa nigeriana tem sido confrontada com novas variáveis na sua dimensão regional (com claras implicações internas), nomeadamente a ascensão da Irmandade Muçulmana no Egito e a proliferação de armas bem como a expansão do terrorismo e do crime organizado transnacional na África Ocidental (Okereke, 2012: 4). Estas novas fontes de insegurança colocam desafios não só à segurança regional em África como à segurança nacional nigeriana. A «insurgência do Boko Haram no norte da Nigéria intensificou-se como resultado do fluxo de armas provenientes da Líbia» (Okereke, 2012: 4). A Nigéria reconhece que a paz e segurança da região estão diretamente ligadas à paz e segurança internas. Esta relação é particularmente visível na ameaça do Boko Haram e das suas ligações a organizações terroristas em África, como a Al Qaeda no Magreb Islâmico (Okereke, 2012). O envolvimento ativo da ECOWAS no Mali vai ao encontro desta preocupação, uma vez que pretende conter a expansão do Boko Haram e dos grupos da Al Qaeda para a Nigéria e os países vizinhos (Okereke, 2012). A UA e a ECOWAS solicitaram conjuntamente à Nigéria apoio para a intervenção no Mali. Esta participação da Nigéria é crucial uma vez que a África do Sul se encontra geograficamente mais distante do Mali, o Egito e a Líbia continuam a gerir desafios internos e a Argélia mantém-se relutante em envolver-se militarmente no Mali (Okereke, 2012). Consequentemente, a liderança desta iniciativa recai quase inevitavelmente na Nigéria. Relativamente aos desafios colocados 
pelo grupo Boko Haram, é importante sublinhar que nos últimos anos este beneficiou de quadros de colaboração e cooperação limitados na área da segurança entre o governo nigeriano e os países vizinhos, em particular os Camarões, o Níger e o Chade. Enquanto as fronteiras entre estes países continuarem porosas e a cooperação na área da segurança se mantiver frágil ou pouco prioritária, continuarão a servir de canais essenciais através dos quais o Boko Haram poderá reforçar o seu poder e os seus meios e recursos (ICG, 2015).

\section{Dimensão internacional}

A dimensão internacional da política externa nigeriana, apesar de ter tido momentos de assertividade unilateral, tem-se pautado por uma ênfase nos princípios de direito internacional. Assim, a Nigéria recém-independente rapidamente se tornou membro da Organização das Nações Unidas, do Movimento dos Não Alinhados e do Grupo dos 77, bem como da Commonwealth of Nations. Apesar de Balewa (1960-1966) ser criticado pela sua tendência pró-ocidental e o seu conservadorismo demasiado colado à herança colonial britânica, o seu governo procurou passar a imagem de um país preocupado em aumentar o poder dos países em desenvolvimento no sistema internacional. Para esse efeito, a Nigéria, por exemplo, participou, entre outras, na criação da Associação de Produtores de Chocolate, no sentido de aumentar o poder negocial internacional desses produtores, com o objetivo de obter uma melhoria dos termos de troca.

A era dos regimes militares (1966-1998) manteve esta ênfase na participação em organizações internacionais, com a entrada da Nigéria na Organização de Produtores e Exportadores de Petróleo (OPEP), no Fundo Monetário Internacional, no Banco Mundial e ainda com a sua assinatura do General Agreement on Trade and 
Tariffs (GATT). De referir, que a Nigéria também se envolveu nas negociações das Convenções de Lomé com a então Comunidade Económica Europeia (CEE), chegando mesmo a liderar algumas das negociações em nome do continente africano. Durante a primeira fase dos regimes militares, com Gowon (1966-1975) e Mohammed/ Obasanjo (1975-1979), a participação da Nigéria nestas organizações foi marcada pelos seus esforços na luta contra o domínio colonial em África e contra o apartheid na África do Sul.

Na segunda fase da época militar (1979-1998), a Nigéria conseguiu uma maior visibilidade para o seu país no palco institucional internacional. O reconhecimento da Nigéria como um líder regional ao nível internacional foi conseguido durante os primeiros governos desta fase com Shagari (1979-1983) e Buhari (1984-1985), mas, essencialmente, com Babangida (1985-1993). A Nigéria ocupou vários cargos em diferentes organizações durante este período que lhe valeram uma visibilidade positiva, de respeito e confiança: Presidente do Comité Anti-Apartheid da ONU, Presidente da $44 .^{a}$ Sessão da Assembleia Geral das Nações Unidas e Secretário-Geral da Commonwealth of Nations (1990-2000). A Nigéria desenvolveu ainda esforços para que o General Osabanjo fosse eleito Secretário-Geral das Nações Unidas, no entanto, sem sucesso. Durante este período, a Nigéria conseguiu ainda que a $13^{\text {a }}$ Sessão Especial da Assembleia Geral das Nações Unidas fosse dedicada à situação económica crítica em África. E, finalmente, para além de ter assumido um papel de responsabilidade regional ao participar nos esforços regionais de paz da ECOWAS na Libéria e Serra Leoa, quando as Nações Unidas enfrentavam problemas de recursos, a Nigéria ainda participou nas missões de paz da ONU na Somália, ex-Jugoslávia e Bosnia-Herzegovina. Esta foi a época áurea da Nigéria no sistema internacional demonstrando um compromisso e empenho claros em seguir e defender as regras de direito internacional e em contribuir para os esforços coletivos nesse sentido. 
Com o regime de Abacha (1993-1998), a imagem internacional da Nigéria sofreu uma deterioração drástica. A violência interna do regime militar levou à suspensão da Nigéria da Commonwealth of Nations, em 1995, após a execução de ativistas opositores ao regime, bem como a uma condenação veemente por parte da Comissão Social, Humanitária e Cultural da Assembleia das Nações Unidas. Ainda assim, a Nigéria ocupou o cargo de Secretário-Geral da OPEP durante este período. A transição para um regime democrático foi assegurada por Abubakar (1998-1999), o qual encetou esforços para recuperar a imagem anterior do seu país no sistema internacional, recebendo mesmo o Secretário-Geral das Nações Unidas, Kofi Annan, em 1998, como um gesto de abertura da Nigéria a uma mudança estrutural do seu regime de governação. Já com Obasanjo (1999-2007), presidente eleito por dois mandatos, a Nigéria retoma um pouco da imagem passada ao presidir o G77, em 2000, e assim assumir um papel de liderança nas relações entre os países em vias de desenvolvimento e o G8. Salienta-se particularmente a sua participação em várias missões de paz das Nações Unidas no continente africano: UNAMSIL (1999-2004, Serra Leoa), UNMIL (2003, Libéria), UNOCI (2004, Costa do Marfim), UNMIS (2005, Sudão), MONUC (2007, República Democrática do Congo), UNAMID (2007, Darfur), MINURSO (2010, Sahara Ocidental), MINURCAT (2010, Chade e República Centro-Africana) e MINUSMA (2013, Mali). Esta estratégia revela uma mudança e uma preocupação em assumir a sua responsabilidade ao nível de hard power nos esforços de paz regionais mas, ao contrário do passado, privilegiando os mecanismos multilaterais. Acresce ainda que, com o fim do apartheid na África do Sul e o aproximar de posições, regional e internacionalmente, entre os dois países, a Nigéria tem vindo a reivindicar dois lugares permanentes no Conselho de Segurança das Nações Unidas, assumindo assim o papel de liderança que a África do Sul tem vindo a desenvolver quer regional, quer internacionalmente. Em abril de 
2014, a Nigéria foi finalmente eleita para o Conselho de Segurança das Nações Unidas, permitindo-lhe uma maior influência a nível das questões relacionadas com a sua estabilidade e segurança interna e/ou regional.

Nas suas relações bilaterais fora do continente africano, a Grã-Bretanha naturalmente assume uma posição de destaque. Logo após a independência, Balewa (1960-1966) foi duramente criticado pela manutenção da dependência relativamente à ex-metrópole, tendo mesmo sido assinado um Pacto de Assistência Mútua entre os dois países. Mas, ainda na década de 1960, com a Guerra Civil no Biafra, a Grã-Bretanha recusou financiar a compra de armas ao governo nigeriano na sua luta armada contra o movimento secessionista no leste do país. Ainda assim, as relações com a Grã-Bretanha mantiveram-se estratégicas e amistosas, tendo-se apenas tornado turbulentas com Mohammed e Obasanjo (1975-1979). Esta mudança deve-se, em parte, ao facto dos dois países se terem tornado concorrentes internacionais no mercado petrolífero, mas mais importante porque a política externa nigeriana entrou em rota de colisão com a britânica no que dizia respeito à sua política externa para com a África do Sul, sem uma condenação veemente do apartheid. Na segunda metade dos regimes militares, a situação foi-se agudizando episódio a episódio. Com Buhari (1984-1985) e a sua política de 'olho-por-olho e dente-por-dente', em 1985, a Nigéria responde à detenção de um avião nigeriano em Londres com a detenção de um avião britânico em Lagos. Acresce ainda que nos seus esforços para recuperar o dinheiro desviado pelos seus antecessores, Buhari depara-se com a posição intransigente da Grã-Bretanha, entre outros países, no sentido de extraditar os alegados 'corruptos e ladrões' que se tinham instalado em terras de sua majestade. Babangida (1985-1993) chega mesmo a boicotar os jogos da Commonwealth of Nations em 1989 como protesto pelo facto de a Grã-Bretanha continuar a não tomar uma posição contra 
ao apartheid. Convém referir que estas tensões nunca afetaram as relações comerciais entre os dois países ao longo das décadas. As demonstrações de força referidas ilustram apenas tomadas de posição simbólicas de parte a parte. Com a eleição de Obasanjo (1999-2003 e 2003-2007) e o fim do apartheid na África do Sul, as relações entre a Nigéria e a Grã-Bretanha deixaram de ter focos de tensão recorrentes. Obviamente que o facto da Grã-Bretanha, conjuntamente com a Suíça, os EUA e a Alemanha, terem garantido a Obasanjo a recuperação do dinheiro desviado por governantes anteriores, constituiu um elemento crucial na consolidação de uma aliança estratégica entre os dois países.

As relações da Nigéria com os EUA e a União Soviética/Rússia foram e têm sido marcadas pelas dinâmicas globais da Guerra Fria e do pós-Guerra Fria. A Nigéria é membro do Movimento dos Não Alinhados, tendo, no entanto, ao longo do período da Guerra Fria, tomado posições mais pró-ocidentais ou pró-bloco de leste, conforme os temas e os governos. Balewa (1960-1966) nunca escondeu a sua postura pró-ocidental e de quase hostilidade para com a ex-União Soviética e o bloco de leste. Com a recusa dos países ocidentais financiarem os esforços de guerra nigerianos no Biafra e o facto da União Soviética ter vindo em auxílio da Nigéria, as relações com os países do bloco de leste desenvolveram-se de forma sólida, passando-se a assistir a um «desafio vigoroso à hegemonia ocidental global» (Abegunrin, 2001: 109), na última metade da década de 1960. Esta posição antiocidental mantém-se com Mohammed/Obasanjo (1975-1979). A Nigéria chega mesmo a cancelar a visita de Henry Kissinger ao país, aquando da realização de um périplo africano no sentido de persuadir os Chefes de Estado a não aderirem ao comunismo e a não seguirem a liderança da Nigéria no reconhecimento do governo angolano do MPLA (Abegunrin, 2003: 66).

A segunda metade da época dos regimes militares engloba o final da Guerra Fria, com uma posição pró-ocidental entusiasta por 
parte de Babangida (1985-1993): apoio tácito à Guerra do Golfo e acolhimento da Convenção de Lomé IV (Garuba, 2008). No entanto, com o regime violento de Abacha (1993-1998), a Nigéria volta a assumir uma posição antiocidental hostil (Abegunrin, 2001: 127). Este antiocidentalismo era privilegiadamente canalizado contra os EUA que desenvolviam esforços para aplicar sanções e um embargo petrolífero à Nigéria, despoletados pela execução de nove ativistas em 1995. Abacha acusava os países ocidentais de "encorajarem ativamente grupos de oposição [na Nigéria] bem como no estrangeiro» contra o seu governo (Abegunrin, 2001: 127).

Com as eleições democráticas em 1999, as relações com o Ocidente e, em especial, com os EUA alteraram-se drasticamente. Em 1999, a Nigéria e os EUA assinaram um acordo que levantou finalmente as restrições de voos diretos entre os dois países (restrições aplicadas desde Abacha) (Garuba, 2008). Apesar desta alteração, continuam a existir momentos de tensão sobre um ou outro tema. Recentemente, a posição nigeriana contra o estabelecimento de um comando militar americano em África (AFRICOM) constituiu um desses momentos (Garuba, 2008). O período pós-2001 proporcionou, no entanto, um novo ímpeto para as relações Nigéria-EUA, nomeadamente na área da cooperação para o desenvolvimento associada ao combate ao Síndrome da Imunodeficiência Adquirida (SIDA) e na luta contra o terrorismo. A Nigéria é um dos quinze países classificados como prioritários para o Plano de Emergência para o SIDA do Presidente dos Estados Unidos da América (PEPFAR) criado em 2004. Este Plano baseia-se na ideia que para além da tragédia humana per se, o impacto do SIDA na Nigéria cria condições para a existência de uma base de recrutamento mais fácil para movimentos extremistas, devido ao elevado número de jovens órfãos. Apesar de esta teoria não ser consensual, o facto é que a Nigéria é um dos países que mais apoio recebe dos EUA através deste Plano (cerca de 1,5 mil mi- 
lhões de dólares americanos). Acresce ainda, que a Nigéria tem sido considerada uma fonte de ameaças à segurança regional na África Ocidental, devido às redes de atividades criminosas e à proliferação de armas e grupos armados, facilitadas por uma estrutura política corrupta e muitas vezes omissa. Desde 2005, a Nigéria confirmou-se como um dos aliados dos EUA no continente africano na luta contra o terrorismo, recebendo ajuda no âmbito da Iniciativa Contra o Terrorismo do Trans-Sahara e da Operação Liberdade Duradoura no Trans-Sahara, ambas enquadradas nas atividades do AFRICOM.

Obviamente que a Nigéria mantém relações diplomáticas e comerciais com vários outros países, mas para além dos países acima referidos, talvez o que mais se destaca atualmente seja a China. A relação entre estes dois países passou de inexistente, com a recusa de Balewa (1960-1966) em reconhecer diplomaticamente o então governo da República Popular da China, a uma relação bastante forte no início do século XXI. Em 2007, a Nigéria constituía praticamente o segundo maior parceiro comercial da China, tendo quadruplicado as suas exportações, que não petróleo, entre 1998 e 2001 (Taylor, 2007). De assinalar também que, em 2006, a Nigéria tornou-se o primeiro país africano a assinar, com Pequim, um Memorando de Entendimento sobre a Criação de uma Parceria Estratégica entres os dois países (Taylor, 2007). A China tem apostado numa política de longo prazo na Nigéria, investindo em infraestruturas e canalizando uma percentagem significativa do seu investimento direto estrangeiro para a economia nigeriana. O impacto estrutural que esta estratégia possa vir a ter na política externa nigeriana não é ainda claro. Por um lado, a relação com a China tem criado alguma tensão interna devido às práticas chinesas de gestão fabril. Por outro, a Nigéria não tem sido um parceiro submisso nesta relação, pois, não só tem apostado na diversificação das suas fontes de recursos na área da ajuda pública ao desenvolvimento, como tem defendido de forma 
assertiva os interesses nacionais em matéria de direitos e benefícios associados à exploração petrolífera ${ }^{110}$.

A riqueza petrolífera nigeriana tem constituído um elemento estruturante da sua política externa a nível internacional. Por um lado, tem proporcionado meios para concretizar as suas decisões. O financiamento de senadores e líderes afro-americanos dos EUA, durante o regime Abacha (1993-1998), no sentido de estes fazerem pressão contra a proposta de aplicação de sanções comerciais e de um embargo petrolífero à Nigéria (Abegunrin, 2003: 154), é um exemplo claro da capacidade que os rendimentos do petróleo proporcionaram. Por outro lado, as dinâmicas associadas às crises petrolíferas da década de 1970 também afetaram negativamente a situação económica nigeriana. Esta é uma situação particular, pois a Nigéria é um país da OPEP. Neste caso, as dinâmicas internas nigerianas tiveram um impacto direto na sua capacidade para enfrentar a crise financeira internacional. Regimes corruptos (Babangida, 1985-1993 e Abacha, 1993-1998), com desvio de fundos para o estrangeiro e conflitos violentos internos, afetando a estabilidade da produção petrolífera, diminuíram de forma estrutural a capacidade dos governos lidarem com a crise económica e financeira. Ainda assim, a Nigéria tentou manter sempre a sua independência, por exemplo, fazendo frente ao FMI, ao não aceitar as condições para o reescalonamento da sua dívida externa no início da década de 1980. O regime Babangida (1985-1993), no entanto, acabou por adotar medidas económicas que, na verdade, eram coerentes com os Programas de Ajustamento Estrutural do FMI (Garuba, 2008). Em 2005, o Clube de Paris finalmente decidiu perdoar cerca de $80 \%$ da dívida externa nigeriana (Pham, 2007), aliviando de forma estrutural

110 Para uma análise do tipo de contratos desenvolvidos pela Nigéria para a exploração petrolífera com empresas estrangeiras, ver (Taylor, 2007). 
as pressões económicas externas com que o país se debatia desde o final da década de 1970.

\section{Considerações finais}

A Nigéria tem sido recorrentemente referida como um 'gigante com pés de barro', caracterizada por uma estrutura económica, política e social frágil que não tem permitido a concretização do seu destino de líder da África negra. Esta fragilidade tem sido acompanhada pela ausência de uma estratégia coerente de política externa e reforçada pelo surgimento e afirmação de outras potências regionais africanas e internacionais. Na verdade, um dos traços mais marcantes da política externa nigeriana desde a independência, e que é transversal às três dimensões analisadas, tem sido a incoerência da mesma. Nesse sentido, e uma vez que a política externa nigeriana foi sempre dependente das dinâmicas de estabilidade e instabilidade que têm caracterizado o país, a Nigéria continua a enfrentar desafios de natureza essencialmente interna com os quais o Presidente eleito em 2015, Muhammadu Buhari, terá de lidar: a consolidação da sua democracia e dos princípios de boa governação, a distribuição equitativa da riqueza nacional, o combate à corrupção, a gestão pacífica dos conflitos internos violentos, e o combate ao HIV-SIDA. De referir que estes desafios internos estão atualmente muito centrados na questão do combate ao Boko Haram e às suas ligações transnacionais na região. Esta ameaça constitui um teste crucial não só à unidade interna da Nigéria, mas também à sua capacidade enquanto líder regional do continente africano (Dersso, 2014; The Guardian, 2015). 


\begin{tabular}{|c|c|c|c|}
\hline Datas & Tipo de regime & Datas & Chefe de estado \\
\hline 一 & - & \multirow{2}{*}{$1960-1966$} & \multirow{2}{*}{ Balewa (não eleito) } \\
\hline $1963-1966$ & 1. ${ }^{\mathrm{a}}$ República & & \\
\hline \multirow{4}{*}{ 1966-1979 } & \multirow{4}{*}{ Militar } & 1966 & Ironsi \\
\hline & & $1966-1975$ & Gowon \\
\hline & & $1975-1976$ & Mohammed \\
\hline & & $1976-1979$ & Obasanjo \\
\hline $1979-1983$ & 2. ${ }^{\mathrm{a}}$ República & $1979-1983$ & Shagari (não eleito) \\
\hline \multirow{5}{*}{$\begin{array}{l}\text { 1983-1999 } \\
{[1993]}\end{array}$} & \multirow{5}{*}{$\begin{array}{l}\text { Militar } \\
\text { [3. }{ }^{a} \text { República (abortada)] }\end{array}$} & $1983-1985$ & Buhari \\
\hline & & $1985-1993$ & Babangida \\
\hline & & 1993 & Shonekan \\
\hline & & 1993-1998 & Abacha \\
\hline & & 1998-1999 & Abubakar \\
\hline \multirow{6}{*}{ 1999- } & \multirow{6}{*}{ 4. ${ }^{\mathrm{a}}$ República } & $1999-2003$ & Obasanjo \\
\hline & & 2003-2007 & Obasanjo \\
\hline & & $2007-2010$ & Yar'Adua \\
\hline & & $2010-2011$ & Jonathan \\
\hline & & 2011-2015 & Jonathan \\
\hline & & 2015- & Buhari \\
\hline
\end{tabular}

\begin{tabular}{|l|}
\hline Quadro 1. \\
\hline Questões para análise \\
\hline A riqueza petrolífera pode ser considerada uma 'maldição' para a política externa nigeriana? \\
\hline Analise criticamente a analogia da Nigéria a um 'gigante com pés de barro'. \\
\hline Considera que a Nigéria está 'destinada' a liderar África'? \\
\hline Concorda que a política externa da Nigéria tem sido demasiado centrada em África? \\
\hline
\end{tabular}

\begin{tabular}{|c|}
\hline Quadro 2. \\
\hline Fontes na internet \\
\hline The Nigerian Economic Summit Group, http://www.nigerianeconomicsummit.org/ \\
\hline The National Think Thank Project, http://www.nationalthinktank.org/index.php \\
\hline Página oficial do Governo da República Federal da Nigéria, http://www.nigeria.gov.ng/ \\
\hline $\begin{array}{l}\text { Ministério dos Negócios Estrangeiros da República Federal da Nigéria, http://www.mfa.gov. } \\
\text { ng/index2.php }\end{array}$ \\
\hline Presidente da Nigéria, http://www.nigeriafirst.org/president.shtml \\
\hline The Nigerian Tribune, http://www.tribune.com.ng/index.php \\
\hline
\end{tabular}




\begin{tabular}{|c|}
\hline Quadro 3. \\
\hline Leituras recomendadas \\
\hline $\begin{array}{l}\text { Babarinde, Olufemi A. e Wright, Stephen (2013) "Nigerian Foreign Policy: Unfulfilled Promise", } \\
\text { in Beasley, Ryan K.; Kaarbo, Juliet; Lantis, Jeffrey S.; Snarr, Michael T. (org), Foreign Policy in } \\
\text { Comparative Perspetive: Domestic and International Influences on State Behavior. Thousand Oaks: } \\
\text { CQ Press. }\end{array}$ \\
\hline $\begin{array}{l}\text { Bach, Daniel (2007) "Nigeria's 'manifest destiny' in West Africa: dominance without power", } \\
\text { Afrika spectrum, 2: 301-321. }\end{array}$ \\
\hline $\begin{array}{l}\text { King, Mae C. (1996) Currents of Nigerian Foreign Policy. Washington D.C.: Howard University } \\
\text { Press. }\end{array}$ \\
\hline $\begin{array}{l}\text { Morgan, Denny and Webber, Mark (2002) "Sub-Saharan Africa: Nigeria and South Africa», in } \\
\text { Webber, Mark; Smith, Michael and with David Allen, Alan Collins, Denny Morgan and Anoushiravan } \\
\text { Ehteshami (org), Foreign Policy in a transformed world. Essex: Prentice-Hall. }\end{array}$ \\
\hline $\begin{array}{l}\text { Oby, Cyril I. (2008) "Nigeria's foreign policy and transnational security challenges in West } \\
\text { Africa", Journal of Contemporary African Studies, 26(2): 183-196. }\end{array}$ \\
\hline $\begin{array}{l}\text { Rotberg, Robert I. (2004) «Trouble Nigeria: Great Opportunies, Tough Challenges", in Rotberg, } \\
\text { Robert I. (org) Crafting the New Nigeria: Confronting the Challenges. Boulder: Lynne Rienner } \\
\text { Publishers Inc.: 1-15. }\end{array}$ \\
\hline
\end{tabular}

\section{Bibliografia}

Abegunrin, Olayiwola (2001) "A Survey of Nigerian Foreign Policy: 1960-1998", in Ojo, Bamidele A. (org) Problems and Prospects of Sustaining Democracy in Nigeria: Voices of a Generation. New York: Nova Science Publishers, Inc.

Abegunrin, Olayiwola (2003) Nigerian Foreign Policy under Military Rule, 1966-1999. Westport: Praeger Publishers.

Adebajo, Adekeye (2002) Building Peace in West Africa: Liberia, Sierra Leone and Guinea-Bissau. Boulder: Lynne Rienner Publishers.

Adebajo, Adekeye and Mustapha, Abdul Raufu (org) (2008) Gulliver's Troubles: Nigeria's Foreign Policy after the Cold War. Durban: University of KwaZulu-Natal Press.

Agbu, Osita; Okereke, Emeka; Wapmuk, Sharkdam e Adeniyi, Bashiru (2013) "The foreign policy environment in Nigeria and implications for Nigeria-South Africa relations: Baseline study", SAFPI Policy Brief 54. [http://www.safpi.org/sites/ default/files/publications/SAFPI_Policy_Brief_54.pdf] (consultado a 1 de abril de 2015).

Ajibewa, Aderemi (1998) "The Third Republic and Nigeria's Foreign Policy Options", in Ojo, Bamidele A. (org) Nigeria's Third Republic: The Problems and Prospects of Political Transition to Civil Rule. Cornmack: Nova Science Publishers, Inc.: 83-100.

African Development Bank (2013) Country Strategy Paper (2013-2017) República Federal da Nigéria. [http://www.afdb.org/fileadmin/uploads/afdb/Documents/ Project-and-Operations/Nigeria\%20-\%202013-2017\%20-\%20Country\%20Strategy $\% 20$ Paper.pdf. (consultado a 2 de março de 2015). 
BBC (2014) "Nigeria becomes Africa's biggest economy», BBC News, 6 abril. [http:// www.bbc.com/news/business-26913497] (consultado a 4 de março de 2015).

BBC (2013) «Nigeria to 'withdraw some troops from Mali'», BBC News, 19 julho. [http://www.bbc.com/news/world-africa23369865] (consultado a 4 de março de 2015).

Bloomberg (2014) "Nigerian Economy Overtakes South Africa's on Rebased GDP", BloombergBusiness, 7 abril. [http://www.bloomberg.com/news/articles/2014-04-06/nigerian-economy-overtakes-south-africa-s-on-rebased-gdpl (consultado a 4 de março de 2015).

Dersso, Solomon (2015) "Badluck Jonathan: Nigerian security trumps democracy", AlJazeera, 10 fevereiro. [http://www.aljazeera.com/indepth/opinion/2015/02/ badluck-jonathan150210053307570.html] (consultado a 2 de março de 2015).

Ford, Jolyon (2012) "Nigeria: a 'pivotal power' in emerging markets?», African Arguments, 2 março. [http://africanarguments.org/2012/03/01/nigeria-a\%E2\%80\%98pivotal-power\%E2\%80\%99-in-emerging-markets-by-jolyon-ford-at-oxford-analytica/nigerian-oil-bill/] (consultado a 2 de março de 2015].

Garuba, Dauda (2008) CIDOB International Yearbook 2008: Keys to Facilitate the Monitoring of the Spanish Foreign Policy and the International Relations in 2007 - Country Profile: Nigeria and its regional context. Barcelona: Fundación CIDOB.

International Crisis Group (2015) "The soldiers are less motivated than the Boko Haram insurgents", In Pursuit of Peace Blog, 18 janeiro. [http://blog.crisisgroup. $\mathrm{org} /$ africa/2015/01/18/the-soldiers-are-less-motivated-than-the-boko-haram-insurgents/] (consultado a 23 de janeiro de 2015).

Ihonvbere, Julius Omozuanvbo (1994) Nigeria: the politics of adjustment and democracy. New Brunswick: Transaction Publishers.

Inamete, Ufot Bassey (2001) Foreign Policy Decision-Making in Nigeria. Cranbury, N.J.: Rosemont Publishing \& Printing Corp.

Maier, Karl (2000) The House Has Fallen. Midnight in Nigeria. Lagos: Public Affairs.

MacGregor, Andrew (2013) Nigerian Army Abandons Peacekeeping Missions in Mali and Darfur to Combat Boko Haram, 9 agosto. [http://www.refworld.org/ docid/5204fb024.html] (consultado a 2 de março de 2015).

Nuamah, Rosemary (2003) Nigeria's Foreign Policy after the Cold War: Domestic, Regional and External Influences. Oxford: International Peace Academy, University of Oxford.

Okereke, C. Nna-Emeka (2012) «Nigeria and the African Union in Light of the Arab Revolts", Lecture Series on African Security 2012. The Nordic Africa Institute. [http:// www.foi.se/Global/V\%C3\%A5r\%20kunskap/S\%C3\%A4kerhetspolitiska\%20studier/ Afrika/Eriksson\%20och\%20Gelot,\%20Focus\%20Nigeria\%20-\%20the\%20AU\%20in\%20 the $\% 20$ Light $\% 20$ of $\% 20$ the $\% 20$ Arab\%20Spring.pdf] (consultado a 1 de abril de 2015).

Pham, Peter J. (2007) «Nigeria's Foreign Policy: An Inquiry into Sources and Prospects». Paper presented at V FLAD-IPRI International Conference: "The EU and Africa: Looking for Strategic Partnership". Lisboa, 8-9 novembro.

Sachs, Goldman (2007a) «BRICs and beyond». [http://www.goldmansachs.com/our-thinking/archive/archive-pdfs/brics-book/brics-full-book.pdf] (consultado a 2 de março de 2015). 
Sachs, Goldman (2007b) «The N11: More than an Acronym». [http://www.goldmansachs. com/our-thinking/archive/archive-pdfs/brics-book/brics-chap11.pdf] (consultado a 2 de março de 2015).

Simon, Okolo Ben (2014) "2015 and the survival of the Nigerian State", African Security Review, 23(2), 161-171.

Taylor, Ian (2007) "China's Relations with Nigeria", The Round Table, 96(392), 631-645 .

The Guardian (2015) "Nigeria's elections promise a genuine contest - but avoiding unrest is vital», 16 janeiro. [http://www.theguardian.com/global-development/2015/ jan/16/nigeria-elections-goodluck-jonathan-muhammadu-buhari-prevent-violencel (consultado a 2 de março de 2015).

Zane, Damian (2015) "Nigeria's Goodluck Jonathan: Five reasons why he lost», 31 março. [http://m.bbc.com/news/world-africa32136295] (consultado a 1 de abril de 2015). 